Pontifícia Universidade C $_{\text {atólica }}$

GRAVB.

Viviana Torralba

Influência do método de compactação na permeabilidade de uma mistura colúvio-composto orgânico

Dissertação apresentada como requisito parcial para obtenção do título de Mestre pelo Programa de PósGraduação em Engenharia Civil da PUC-Rio.

Orientadores: Tácio Mauro Pereira de Campos Franklin dos Santos Antunes 


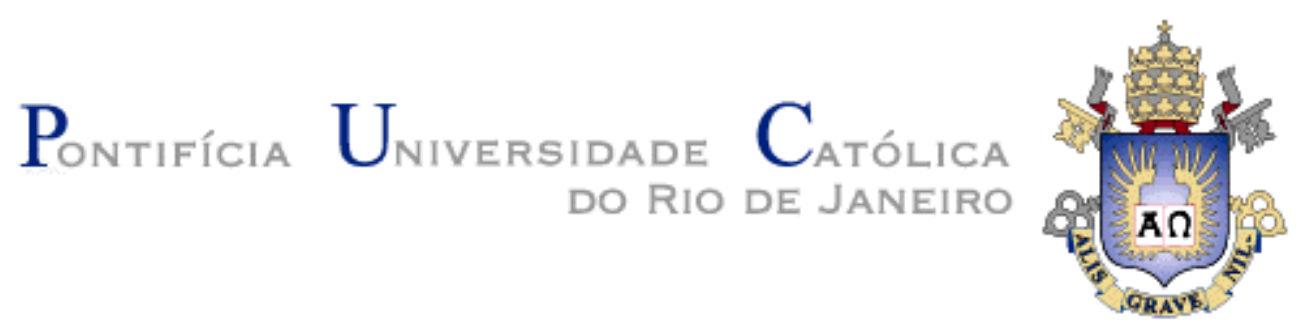

Viviana Torralba

\section{Influência do método de compactação na permeabilidade de uma mistura colúvio-composto orgânico}

Dissertação apresentada como requisito parcial para obtenção do título de Mestre pelo Programa de Pós-Graduação em Engenharia Civil da PUC-Rio. Aprovada pela Comissão Examinadora abaixo assinada.

Tácio Mauro Pereira de Campos

Orientador

PUC - Rio

Franklin dos Santos Antunes

Co-orientador

PUC - Rio

Sérgio Tibana

UENF

Eurípedes do Amaral Vargas Júnior

PUC - Rio

José Eugênio Leal

Coordenador(a) Setorial do Centro Técnico Científico - PUC-Rio

Rio de Janeiro, 17 de janeiro de 2007 
Todos os direitos reservados. É proibida a reprodução total ou parcial do trabalho sem autorização da universidade, da autora e do orientador.

\section{Viviana Torralba}

Graduou-se em Engenharia Civil pela Universidade Latina de Costa Rica em 2003. As principais áreas de interesse e linhas de pesquisa são: mecânica dos solos, geotecnia experimental e geotecnia ambiental.

Ficha Catalográfica

Torralba, Viviana

Influência do método de compactação na permeabilidade de uma mistura colúvio-composto orgânico/Viviana Torralba; orientador: Tácio Mauro Pereira de Campos; co-orientador: Franklin dos Santos Antunes. Rio de Janeiro: PUC, Departamento de Engenharia Civil, 2007.

168 f.; $30 \mathrm{~cm}$

Dissertação (Mestrado) - Pontifícia Universidade Católica do Rio de Janeiro, Departamento de Engenharia Civil.

Inclui referências bibliográficas.

1. Engenharia Civil - Teses. 2. Compactação 3. Permeabilidade 4. Colúvio 5. Composto Orgânico I. Tácio Mauro Pereira de Campos. II. Franklin dos Santos Antunes. III. Pontifícia Universidade Católica do Rio de Janeiro. Departamento de Engenharia Civil. IV. Título 


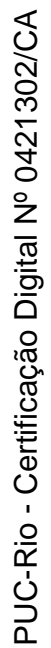

Aos meus pais e irmã. 


\section{Agradecimentos}

Ao Professor Tácio de Campos pela orientação, conhecimentos transmitidos, atenção, apoio e paciência.

Ao Professor Franklin dos Santos Antunes pela sua disposição incondicional, tempo e amizade. Sua ajuda foi um grande aporte neste trabalho.

A todos os professores que, ao longo do meu mestrado, transmitiram seu conhecimento e apoio, especialmente aos professores Sérgio Fontoura e Alberto Sayão.

A Ana Roxo e Rita, por serem sempre tão amáveis e prestativas.

À PUC-Rio por ter me aceitado no programa de pós-graduação e à CAPES pelo apoio financeiro.

Ao Engenheiro William Braga, pela paciente ajuda na execução dos ensaios de permeabilidade e a Amaury, Josué e "Seu" José por estarem disponíveis sempre que precisei.

A todos os brasileiros que me acolheram e aos amigos que me acompanharam durante esse processo e fizeram com que o Brasil se tornasse meu lar, pois nunca me deixaram sentir saudade nem tristeza. Muito pelo contrário, foi graças a vocês que me senti sempre em casa. Sua cultura, seus costumes, seu jeitinho hospitaleiro e carinhoso fizeram com que me apaixonasse pelo seu país e sua gente. Sempre guardarei esta experiência como uma das mais valiosas na minha vida.

Por seu tempo sacrificado para me explicar e ajudar quando tive alguma dificuldade, pelo esforço para me ensinar português e mostrar as coisas lindas da sua cultura, por estar perto de mim em momentos bons e ruins, por serem amigos e amigas de verdade, que me aceitaram do jeito que sou e me fizeram parte dos seus. Álvaro, Ana Lúcia, Carol, Bê, Fer-velhinho, Gui, Lica, Luciana, Saré, Taíse, Tânia, Thaís, Tricia, Vini e Ygor, sempre estarei agradecida com vocês. 
A todos os que estudaram comigo ou se sentiram incomodados com minha voz baixinha na favelinha: Leo, Johan, Julito, Fabio, Tonho, Mariana, Taludes e Jackie. Ao apartamento Paraná (Thais, Pedro, João e Marcelo), porque cada um de vocês me deu ajuda e opinião valiosa. A Amanda pelas maravilhosas receitas e agradável companhia. A todos os amigos das horas de descontração...

Às meninas futura, Bê, Lorraine, Carlinha, Dani e Tricia, pelos ótimos momentos de convivência, por serem minhas irmãzinhas e por me agüentarem! Agradeço especialmente à Lore pelo seu apoio moral e pela "força tecnológica" para concluir o meu trabalho e à Bê, por sua amizade única e incondicional, incapaz de falhar, sempre de primeira para me ajudar com tudo.

A Tri, Ana Lucia, Taíse e Bê por me dar forças e muitas horas de diversão e alegrias.

A Mónica pela sua paciência extrema e sua ajuda incondicional. Sem você, este trabalho não teria sido possível mesmo.

A Denise pela sua excelente disposição e ajuda.

A Julito Macias e Wagner, por todas as conversas, conselhos e valiosa amizade.

Ao velhinho e a Ygor por serem grandes e queridíssimos amigos.

A Renán Espinoza, Sergio Saenz e Fernando Alvarado pelo apoio e ajuda.

Ao Gui, por acreditar em mim mais do que eu mesma, por facilitar as coisas e me fazer sentir sempre tão leve. Por me fazer rir nos momentos difíceis e me levantar nos momentos de fraqueza. Graças ao teu carinho e apoio esta dissertação foi concluída.

A minha família, por todo o amor, apoio e por abrir mão de mim para que pudesse realizar meu sonho. Obrigada por todos os sacrifícios que minha educação significou para vocês. 


\section{Resumo}

Torralba, Viviana; de Campos, Tácio Mauro Pereira; Antunes, Franklin dos Santos. Influência do método de compactação na permeabilidade de uma mistura colúvio-composto orgânico. Rio de Janeiro, 2007. 168 p. Dissertação de Mestrado - Departamento de Engenharia Civil, Pontifícia Universidade Católica do Rio de Janeiro.

O liner é um elemento de extrema importância no processo construtivo de um aterro sanitário, pois funciona como uma barreira capaz de impedir a percolação de agentes contaminantes através do subsolo. Os liners ou camadas impermeabilizantes são geralmente construídos a partir de materiais que possuem baixa permeabilidade. A escolha de um material adequado, assim como o controle dos processos construtivos são indispensáveis para garantir um bom desempenho da camada impermeabilizante. O processo de compactação é de extrema importância neste tipo de obra geotécnica. Os ensaios de compactação realizados em laboratório têm como objetivo reproduzir as condições de campo, no entanto, em numerosos casos há diferenças importantes entre os mecanismos de compactação utilizados, na preparação do material antes do processo de densificação e nas características das amostras, o que gera como conseqüência discrepâncias nos valores de permeabilidade de campo com os de laboratório. O objetivo principal do presente estudo é avaliar experimentalmente a influência de dois mecanismos diferentes de compactação (dinâmico, com o Proctor Normal e estático, com o método de compactação por pisoteamento) nos valores de permeabilidade de um solo coluvionar e de um composto orgânico para seu eventual uso em um liner. Os ensaios foram realizados em corpos de prova com diferentes teores de umidade, preparados com solo coletado no campo Experimental II da PUC-Rio, com composto orgânico produzido a partir do processo de compostagem da grama do Aeroporto Internacional Galeão (RJ), e com misturas em diferentes proporções de ambos os materiais.

\section{Palavras-chave}

Compactação; Permeabilidade; Colúvio; Composto Orgânico; Pisoteamento; Compactador Pneumático; Liner. 


\section{Abstract}

Torralba, Viviana; de Campos, Tácio Mauro Pereira (Advisor); Antunes, Franklin dos Santos (Co-advisor). Effect of the compaction method on the permeability of an organic compound-colluvionar soil mixture. Rio de Janeiro, 2006. 168 p. Msc. Thesis - Civil Engineering Department, Pontifícia Universidade Católica do Rio de Janeiro.

The liner is one of the most important elements in a sanitary landfill project, since it works as a barrier capable to impede seepage of pollutant substances through the subsurface. This element is usually built with materials that have low permeability. The choice of the right material as well as the control and supervision of the constructive processes are fundamental to achieve a good liner performance. The compaction process is extremely important in this type of geotechnical impoundment. Laboratory compaction intends to reproduce the field conditions; however, in some cases, there happen to be important differences between the compaction mechanisms used, the preparation of the material before the densification process and the specimens characteristics, which cause discrepancies between the permeability values obtained in the field and the ones obtained in the laboratory. The main objective of this study is to evaluate experimentally the effect of two different compaction mechanisms (dynamic, with standard Proctor and static, with the kneading compaction method) in the hydraulic conductivity of a colluvionar soil and an organic compound for their eventual use in a liner. The tests were executed using specimens with different water contents, prepared with colluvionar soil extracted from the Experimental Field II at the PUC-Rio, with the organic compound, and with mixtures of both materials in different proportions.

\section{Key Words}

Compaction, permeability; colluvionar soil; organic compound; kneading; kneading compactor; liner. 


\section{Lista de símbolos e abreviações}

\# = diâmetro da abertura da malha da peneira;

$\mathrm{a}=$ massa da amostra seca em estufa, à temperatura de $110^{\circ} \mathrm{C}$;

$\mathrm{A}=$ área transversal do corpo de prova;

$\mathrm{AH}=$ ácido húmicos;

$\mathrm{AH}=$ ácido fúlvicos;

ABNT = Associação Brasileira de Normas Técnicas;

$\mathrm{b}=$ massa da amostra queimada em mufla à temperaturas de $500{ }^{\circ} \mathrm{C}$ ou $400{ }^{\circ} \mathrm{C}$;

$B$ = parâmetro de Skempton;

$\mathrm{CH}=$ Argila inorgânica de alta plasticidade, de acordo com a classificação de solos do SUCS;

$\mathrm{Ct}=$ caulinita;

$\mathrm{CO}=$ composto orgânico;

$\mathrm{CP}=$ corpo de prova;

CTC = capacidade de troca catiônica;

DCMM = Departamento de Ciências dos Materiais e Metalurgia da PUC-Rio;

DRX = difração por raios- $X$;

e = índice de vazios;

EHT = extrato húmico total;

$E P A=$ U.S. Environmental Protection Agency;

$\mathrm{G}_{\mathrm{s}}=$ densidade relativa dos grãos;

$\mathrm{H}_{\mathrm{CP}}=$ altura do corpo de prova;

i = gradiente hidráulico;

$\mathrm{I}_{\mathrm{a}}=$ índice de atividade das argilas;

EMBRAPA= Empresa Brasileira de Pesquisa Agropecuária;

IP = índice de plasticidade;

k = coeficiente de permeabilidade; condutividade hidráulica; 
$\mathrm{LL}=$ limite de liquidez;

LP = limite de plasticidade;

$\mathrm{MO}=$ matéria orgânica;

MO1= ensaio de queima de matéria orgânica a 500ํㅡ durante 4 horas;

MO2= ensaio de queima de matéria orgânica a $400{ }^{\circ} \mathrm{C}$ durante 6 horas;

M1 $=$ mistura 1 , conformada por $75 \%$ de solo coluvionar e $25 \%$ de composto orgânico;

$\mathrm{M} 2=$ mistura 2 , conformada por $50 \%$ de solo coluvionar e $50 \%$ de composto orgânico;

M3 = mistura 3 , conformada por $25 \%$ de solo coluvionar e $75 \%$ de composto orgânico;

$\mathrm{n}=$ porosidade;

PUC-Rio = Pontifícia Universidade Católica do Rio de Janeiro;

$\mathrm{PN}=$ Proctor Normal;

Qt = quartzo;

$\mathrm{Q}=$ vazão;

$\mathrm{R}^{2}=$ coeficiente de correlação;

$S_{0}=$ grau de saturação inicial;

$S$ = grau de saturação;

SUCS = Sistema Unificado de Classificação de Solo;

$\mathrm{t}=$ tempo;

UFRJ = Universidade Federal do Rio de Janeiro;

UNAM = Universidade Nacional Autônoma de México;

$\mathrm{w}_{\mathrm{o}}=$ teor de umidade de compactação;

$\mathrm{w}_{\mathrm{f}}=$ teor de umidade final;

$\mathrm{w}_{\mathrm{ot}}=$ umidade ótima;

$\mathrm{W}_{\mathrm{ot}+3 \%}=$ três pontos percentuais acima da umidade ótima; umidade ótima mais três por cento; 
$\mathrm{W}_{\mathrm{ot}-3 \%}=$ três pontos percentuais abaixo da umidade ótima; umidade ótima menos três por cento;

x, y = parâmetros de ajuste das linhas de tendência;

$\rho_{d}=$ massa específica seca;

$\sigma^{\prime}=$ tensão efetiva utilizada no ensaio de permeabilidade;

$\Delta \sigma_{\mathrm{c}}=$ acréscimo de tensão confinante aplicado;

$\Delta \mathrm{t}=$ variação de tempo;

$\Delta \mathrm{u}=$ excesso de poropressão gerado;

$\Delta \mathrm{V}=$ variação de volume . 


\section{Sumário}

1 Introdução 22

2 Revisão Bibliográfica 25

2.1 Camadas impermeabilizantes ou liners 25

2.1.1 Liners de Argila Compactada 27

2.2 Compactação 29

2.2.1 Tipo de Solo 31

2.2.2 Umidade de Compactação 32

2.2.3 Métodos e Energia de Compactação 32

2.2.4 Estrutura do Solo 34

2.2.5 Importância do processo de compactação na construção de um liner 37

2.2.6 Ensaios de laboratório versus compactação de campo 39

2.3 Permeabilidade 41

2.3.1 Geometria de Estrutura Porosa 43

2.3.1.1 Textura do Solo 43

2.3.1.2 Deposição Natural e Processos de Compactação 44

2.3.2 Propriedades do Fluido Percolante 49

2.3.3 A interação superficial entre o fluido e o meio poroso. 50

2.3.4 Ensaios em laboratório 52

2.3.5 Ensaios de campo versus ensaios de laboratório: determinação da permeabilidade dos liners 53

3 Descrição dos Materiais Utilizados $\quad 56$

3.1 Introdução 56

3.2 Solo 56

3.2.1 Localização $\quad 57$

3.2.2 Geologia e Geomorfologia 58

$\begin{array}{lll}\text { 3.2.3 Aspectos climáticos } & 60\end{array}$

3.2.4 Amostragem do Solo 60

3.3 Composto Orgânico 62

3.3.1 Processo de Obtenção do Composto Orgânico 63

$\begin{array}{lll}\text { 3.3.2 Características da Matéria Orgânica } & 65\end{array}$ 
3.3.3 Preparação do material antes da execução de ensaios 66

$\begin{array}{lll}3.4 & \text { Misturas } & 66\end{array}$

4 Equipamento e Metodologia de Ensaios 68

$\begin{array}{lll}4.1 & \text { Introdução } & 68\end{array}$

4.2 Ensaios de Caracterização 69

$\begin{array}{lll}\text { 4.2.1 Caracterização Física } & 70\end{array}$

$\begin{array}{ll}\text { 4.2.2 Caracterização Mineralógica } & 70\end{array}$

$\begin{array}{lll}\text { 4.2.3 Caracterização Química } & 71\end{array}$

$\begin{array}{lll}4.3 & \text { Ensaios de Compactação } & 72\end{array}$

4.3.1 Proctor Normal 73

$\begin{array}{lll}\text { 4.3.1.1 Descrição do Equipamento } & 73\end{array}$

$\begin{array}{lll}\text { 4.3.1.2 Metodologia do Ensaio } & 74\end{array}$

$\begin{array}{lll}\text { 4.3.2 Pisoteamento } & 76\end{array}$

$\begin{array}{lll}\text { 4.3.2.1 Descrição do Equipamento } & 76\end{array}$

4.3.2.2 Metodologia do Ensaio $\quad 77$

4.3.3 Relação Entre o Ensaio Proctor Normal e Pisoteamento 81

4.4 Ensaios de Permeabilidade 83

4.4.1 Descrição do Equipamento 84

$\begin{array}{lll}\text { 4.4.2 Metodologia do Ensaio } & 87\end{array}$

4.4.2.1 Moldagem dos Corpos de Prova 87

$\begin{array}{lll}\text { 4.4.2.2 Montagem } & 88\end{array}$

$\begin{array}{lll}\text { 4.4.2.3 Saturação } & 91\end{array}$

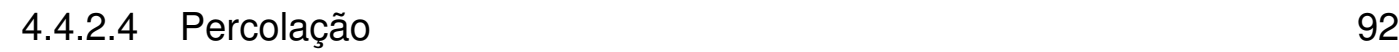

5 Apresentação e Discussão dos Resultados 95

5.1 Introdução 95

5.2 Caracterização Física 95

$\begin{array}{lll}\text { 5.2.1 Granulometria } & 95\end{array}$

5.2.2 Densidade dos Grãos 96

$\begin{array}{lll}\text { 5.2.3 Limites de Consistência } & 97\end{array}$

$\begin{array}{lll}\text { 5.2.4 Classificação } & 99\end{array}$

5.3 Caracterização Mineralógica 99

5.4 Caracterização Química 103

$\begin{array}{ll}5.4 .1 \text { Solo } & 103\end{array}$

$\begin{array}{ll}\text { 5.4.2 Composto Orgânico } & 103\end{array}$

$\begin{array}{lll}5.5 & \text { Ensaios de Compactação } & 106\end{array}$ 
$\begin{array}{lll}\text { 5.5.1 Proctor Normal } & 106\end{array}$

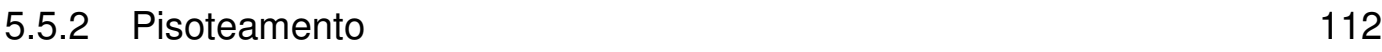

$\begin{array}{ll}5.6 & \text { Ensaios de Permeabilidade } \\ & 119\end{array}$

$\begin{array}{ll}5.6 .1 \text { Solo } & 119\end{array}$

$\begin{array}{lll}5.6 .2 & \text { Mistura } 1 & 125\end{array}$

$\begin{array}{lll}5.6 .3 & \text { Mistura } 2 & 130\end{array}$

$\begin{array}{lll}\text { 5.6.4 } & \text { Mistura } 3 & 135\end{array}$

5.6.5 Comparação conjunta dos resultados dos ensaios de permeabilidade dos materiais em estudo

6 Conclusões e Sugestões 146

6.1 Conclusões 146

$\begin{array}{lll}6.1 .1 & \text { Materiais } & 146\end{array}$

$\begin{array}{lll}\text { 6.1.2 } & \text { Permeabilidade } & 147\end{array}$

6.1.3 Escolha do material para utilizar no liner 150

6.2 Sugestões 150

Referências Bibliográficas 152

Anexo I Micromorfologia de Amostras Compactadas com Proctor Normal e

Pisoteamento 160

Apêndice A Detalhes da Composição Química do Composto Orgânico 164

Apêndice B Detalhes dos permeâmetros flexíveis ligados a frascos de Mariotte para a execução de ensaios de permeabilidade 166 


\section{Lista de figuras}

Figura 2.1-Curva de compactação.

Figura 2.2-Influência da energia de compactação no comportamento do solo (Adaptado de Holtz e Kovacs, 1981).

Figura 2.3-Efeitos da compactação na estrutura do solo (Adaptado de Lambe, 1958).

Figura 2.4-Influência do método de compactação no comportamento do solo (Adaptado de Mitchell et al., 1965).

Figura 2.5-Condutividade hidráulica versus grau de saturação (Adaptado de Olson e Daniel, 1981).

Figura 2.6-Coeficiente de permeabilidade de três argilas com diferentes tamanhos de grãos (Adaptado de Mesri e Olson, 1971).

Figura 2.7-Estruturas dispersa e floculada respectivamente (Lambe, 1958).

Figura 2.8-Fluxo de água através de poros relativamente grandes entre os grumos (Olsen, 1962).

Figura 2.9-Influência dos grumos na condutividade hidráulica para ensaios realizados em permeâmetros com parede rígida e flexível em amostras compactadas com Proctor Normal e Modificado.

Figura 2.10-Variação da condutividade hidráulica da esmectita com fluidos percolantes de diferente composição química (Adaptado de Mesri e Olson, 1971).

Figura 2.11-Permeâmetro de parede flexível usado em laboratório (Adaptado de Daniel et al., 1984).

Figura 3.1-Localização do Campo Experimental II, PUC-Rio (Soares, 2005). 58 Figura 3.2-Perfil morfológico do local de estudo (Daylac, 1994).

Figura 3.3-Retirada da amostra deformada no Campo Experimental II da PUCRio.

Figura 3.4-Profundidade da escavação para extrair a amostra deformada. 62 Figura 3.5-Visão geral do ensaio de compostagem no primeiro dia (esquerda) e trinta dias depois (direita) (Benites et al. 2004). 
Figura 4.1-Instrumentos do ensaio Proctor Normal.

Figura 4.2-Molde tripartido, base de alumínio e anéis médio e superior de confinamento; amostra de solo obtida a partir do pisoteamento; outros acessórios. 76

Figura 4.3-Compactador Pneumático.

Figura 4.4-Molde cilíndrico tripartido e anéis de confinamento. 78

Figura 4.5-Rotina do ensaio de pisoteamento.

Figura 4.6-Seqüência de pressão aplicada no solo por meio do equipamento de pisoteamento.

Figura 4.7-Relação entre a curva de compactação do Proctor Normal e a curva de massa específica seca vs pressão aplicada (curva de pisoteamento, regressão exponencial) para a determinação da pressão equivalente. 82 Figura 4.8-Sistema de aquisição de dados.

Figura 4.9-Esquema dos permeâmetros (Adaptada de Carvalho, 2006). 85

Figura 4.10-Detalhe permeâmetro de 4 1⁄2 ". 86

Figura 4.11-Montagem do corpo de prova para ensaio de permeabilidade. $\quad 89$

Figura 4.12-Colocação da membrana de látex no corpo de prova com ajuda do encamisador. $\quad 89$

Figura 4.13-Montagem completa do corpo de prova no pedestal. 90

Figura 4.14-Preenchimento da câmara com água. 90

Figura 5.1-Curvas granulométricas dos materiais em estudo. 96

Figura 5.2-Densidade dos grãos vs teor de composto orgânico no material. $\quad 97$

Figura 5.3-Limites de consistência versus teor de composto orgânico. 98

Figura 5.4-Presença da matriz argilosa com grãos de quartzo e granada muito alterada (Soares, 2005). 100

Figura 5.5-Grãos de quartzo arestados e cristais grandes de quartzo (Soares, 2005).

Figura 5.6-Grande área da matriz argilosa englobando alguns grãos de agregados ferruginosos e quartzo (Soares, 2005).

Figura 5.7-Difratograma da amostra de solo passante na peneira \#200 (Legenda: $\mathrm{Ct}=$ Caulinita, $\mathrm{Qt}=\mathrm{Quartzo})$.

Figura 5.8-Recipientes com composto orgânico seco em estufa a $110^{\circ} \mathrm{C}$ antes de ser colocado na mufla.

Figura 5.9-Recipientes com composto orgânico após ser submetido à queima na mufla. 
Figura 5.10-Curva de compactação Proctor Normal, Solo. 107

Figura 5.11-Curva de compactação Proctor Normal, M1. 108

Figura 5.12-Curva de compactação Proctor Normal, M2. 109

Figura 5.13-Curva de compactação Proctor Normal, M3. 110

Figura 5.14-Curva de compactação Proctor Normal, Composto Orgânico. 111

Figura 5.15-Definição de pressão equivalente com pisoteamento para o solo. 112

Figura 5.16-Definição de pressão equivalente com pisoteamento para M1. 113

Figura 5.17-Definição de pressão equivalente com pisoteamento para M2. 113

Figura 5.18-Definição de pressão equivalente com pisoteamento para M3. 114

Figura 5.19-Corpo de prova deformado devido às elevadas pressões de pisoteamento.

Figura 5.20-Deformação do corpo de prova conseqüente da penetração do equipamento do compactador pneumático.

Figura 5.21-Vista superior do molde de pisoteamento com solo deformado devido às elevadas pressões de compactação.

Figura 5.22-Variação de volume versus tempo, ensaio de permeabilidade do solo com corpos de prova moldados por pisoteamento.

Figura 5.23-Coeficiente de permeabilidade versus tempo para corpos de prova de solo moldados com pisoteamento.

Figura 5.24-Variação de volume versus tempo, ensaio de permeabilidade do solo com corpos de prova moldados por Proctor Normal.

Figura 5.25-Coeficiente de permeabilidade versus tempo para corpos de prova de solo moldados com Proctor Normal.

Figura 5.26-Massa específica seca versus umidade de compactação, solo. 123

Figura 5.27-Índice de vazios versus umidade de compactação, solo.

Figura 5.28-Coeficiente de permeabilidade versus umidade de compactação, solo.

Figura 5.29-Variação de volume versus tempo, ensaio de permeabilidade da M1 com corpos de prova moldados por pisoteamento.

Figura 5.30-Coeficiente de permeabilidade versus tempo para corpos de prova da M1 moldados com pisoteamento.

Figura 5.31-Variação de volume versus tempo, ensaio de permeabilidade da M1 com corpos de prova moldados com Proctor Normal.

Figura 5.32-Coeficiente de permeabilidade versus tempo para corpos de prova da M1 moldados com Proctor Normal. 
Figura 5.33-Massa específica seca versus umidade de compactação, M1. 128

Figura 5.34-Índice de vazios versus umidade de compactação, M1. 129

Figura 5.35-Coeficiente de permeabilidade versus umidade de compactação, M1.1 Figura 5.36-Variação de volume versus tempo, ensaio de permeabilidade da M2 com corpos de prova moldados por pisoteamento.

Figura 5.37-Coeficiente de permeabilidade versus tempo para corpos de prova da M2 moldados com pisoteamento.

Figura 5.38-Variação de volume versus tempo, ensaio de permeabilidade da M2 com corpos de prova moldados por Proctor Normal.

Figura 5.39-Coeficiente de permeabilidade versus tempo para corpos de prova da M2 moldados com Proctor Normal. 133

Figura 5.40-Massa específica seca versus umidade de compactação, M2. 133 Figura 5.41-Índice de vazios versus umidade de compactação, M2. 134 Figura 5.42-Coeficiente de permeabilidade versus umidade de compactação, M2.1 Figura 5.43-Variação de volume versus tempo, ensaio de permeabilidade da M3 com corpos de prova moldados por pisoteamento.

Figura 5.44-Coeficiente de permeabilidade versus tempo para corpos de prova da M3 moldados com pisoteamento.

Figura 5.45-Gráfico de variação de volume versus tempo mostrado a maior escala, ensaio de permeabilidade da M3 com corpos de prova moldados por pisoteamento.

Figura 5.46-Gráfico de coeficiente de permeabilidade versus tempo mostrado a maior escala para corpos de prova da M3 moldados com pisoteamento. 138 Figura 5.47-Variação de volume versus tempo, ensaio de permeabilidade da M3 com corpos de prova moldados por Proctor Normal.

Figura 5.48-Coeficiente de permeabilidade versus tempo para corpos de prova da M3 moldados com Proctor Normal. 139

Figura 5.49-Massa específica seca versus umidade de compactação, M3. 139 Figura 5.50-Índice de vazios versus umidade de compactação, M3.

Figura 5.51-Coeficiente de permeabilidade versus umidade de compactação, M3.1 Figura 5.52-Massa específica seca versus umidade de compactação para o solo e as misturas M1, M2 e M3, compactadas nas umidades $\mathrm{w}_{\mathrm{ot}-3 \%}, \mathrm{w}_{\mathrm{ot}}$ e $\mathrm{w}_{\mathrm{ot}+3 \%} \mathrm{com}$ Proctor Normal e pisoteamento.

Figura 5.53-Índice de vazios versus umidade de compactação para o solo e as misturas M1, M2 e M3, compactadas nas umidades $\mathrm{w}_{\mathrm{ot}-3 \%}, \mathrm{w}_{\mathrm{ot}}$ e $\mathrm{w}_{\mathrm{ot}+3 \%} \mathrm{com}$ Proctor Normal e pisoteamento. 
Figura 5.54-Coeficiente de permeabilidade versus umidade de compactação para o solo e as misturas M1, M2 e M3, compactadas nas umidades $\mathrm{w}_{\mathrm{ot}-3 \%}, \mathrm{w}_{\mathrm{ot}} \mathrm{e}$ $\mathrm{w}_{\mathrm{ot}+3 \%}$ com Proctor Normal e pisoteamento.

Figura I. 1 - Visão geral da estrutura da amostra de solo compactado por Proctor Normal na $\mathrm{W}_{\text {ot }}$ (Aumento:2,5x). 160

Figura I. 2 - Visão geral da estrutura da amostra da M3 compactada por Proctor Normal na $\mathrm{W}_{\text {ot }}$ (Aumento:2,0x).

Figura I. 3 - Visão geral da estrutura da amostra de solo compactada por pisoteamento na $\mathrm{W}_{\text {ot }}$ (Aumento:2,0x).

Figura I. 4 - Visão geral da estrutura da amostra da M3 compactada por pisoteamento na $\mathrm{W}_{\text {ot }}$ (Aumento: 2,0x).

Figura B.1-Permeâmetros de parede flexível com carga constante aplicada por Mariottes. 


\section{Lista de tabelas}

Tabela 2.1-Propriedades do solo para atingir uma condutividade hidráulica media menor ou igual que $1 \times 10^{-7} \mathrm{~cm} / \mathrm{s}$.

Tabela 2.2-Influência do tamanho dos grumos na permeabilidade de argila compactada (Daniel, 1984).

Tabela 3.1-Proporção das misturas solo-composto orgânico.

Tabela 4.1-Resumo de ensaios de caracterização dos materiais em estudo. $\quad 69$ Tabela 4.2 - Resumo do programa de ensaios, caracterização física. $\quad 70$ Tabela 4.3-Altura dos corpos de prova (em centímetros) compactados por pisoteamento, utilizados nos ensaios de permeabilidade.

Tabela 4.4-Altura dos corpos de prova compactados por Proctor Normal, utilizados nos ensaios de permeabilidade.

Tabela 4.5-Ensaios de permeabilidade executados.

Tabela 4.6-Denominação dada aos diferentes ensaios de permeabilidade.

Tabela 5.1-Resumo das características granulométricas dos materiais. 96

Tabela 5.2-Valores de Gs obtidos experimentalmente 97

Tabela 5.3-Limites de consistência, índice de plasticidade e atividade.

Tabela 5.4-Análise mineralógica do solo (Sertã, 1986).

Tabela 5.5-Análises químicas de capacidade de troca catiônica (CTC) e de ataque sulfúrico (Duarte, 2004).

Tabela 5.6-Análise química total em porcentagem em peso (Sertã, 1986). 103

Tabela 5.7-Teor de matéria orgânica do composto utilizado nas misturas. 104

Tabela 5.8-Propriedades do solo quando compactado com Proctor Normal. 107

Tabela 5.9-Propriedades da M1 quando compactada com Proctor Normal. 108

Tabela 5.10-Propriedades da M2 quando compactada com Proctor Normal. 109

Tabela 5.11-Propriedades da M3 quando compactada com Proctor Normal. 110

Tabela 5.12-Propriedades do Composto Orgânico quando compactado com Proctor Normal.

Tabela 5.13-Pressão equivalente para as umidades $\mathrm{W}_{\mathrm{ot}-3 \%}, \mathrm{~W}_{\mathrm{ot}}$ e $\mathrm{W}_{\mathrm{ot}+3 \%}$ com as respectivas massas específicas secas. 
Tabela 5.14-Características iniciais dos corpos de prova do solo para ensaios de permeabilidade. 120

Tabela 5.15-Condições e resultados dos ensaios de permeabilidade no solo. 120 Tabela 5.16-Características iniciais dos corpos de prova de M1 para ensaios de permeabilidade. 126

Tabela 5.17-Condições e resultados dos ensaios de permeabilidade, M1. 126 Tabela 5.18-Características iniciais dos corpos de prova de M2 para ensaios de permeabilidade. 130

Tabela 5.19-Condições e resultados dos ensaios de permeabilidade, M2. 131 Tabela 5.20-Características iniciais dos corpos de prova de M3 para ensaios de permeabilidade. 136 Tabela 5.21-Condições e resultados dos ensaios de permeabilidade, M3. 136

Tabela A. 1-Classificação e características dos insumos orgânicos analisados conforme metodologia adotada pelo Ministério da Agricultura (LANARV, 1988).

Tabela A. 2-Características químicas do composto orgânico obtido a partir de resíduos da manutenção de gramados em áreas urbanas.

Tabela A. 3-Teores de ácidos húmicos $(\mathrm{AH})$, fúlvicos( $\mathrm{AF})$ e extrato húmico total (EHT) do extrato de ácidos húmicos dos insumos orgânicos analisados. 